\title{
SEXING BERDASARKAN MORFOLOGI BURUNG PUYUH (Coturnix coturnix japonica)
}

\author{
Winda Tumbilung, L. Lambey, E.Pudjihastuti, E. Tangkere \\ Fakultas Peternakan Universitas Sam Ratulangi, Manado 95115 \\ E-mail : windatumbilung@gmail.com
}

\begin{abstract}
ABSTRAK
Tujuan penelitian ini untuk mengetahui seberapa besar keberhasilan sexing apabila dilakukan lebih awal.Penelitian ini dilaksanakan di kandang peternakan burung puyuh yang berlangsung mulai 1 April- 18 Mei 2014. Bahan yang digunakan adalah burung jantan dan betina umur 1 hari (Day old quail) sebanyak 110 ekor untuk ulangan 1 dan 100 ekor untuk ulangan 2, ransum komersial CP11, vitastress serta peralatan lainya lampu pijar 60 watt, kandang kotak (brooder), timbangan digital, dan kamera digital. Pengamatan ini dilakukan mulai hari pertama saat puyuh baru menetas sampai umur 3 minggu. Data yang diperoleh dianalisis secara deskriptif. Hasil penelitian menunjukkan sexing dengan melihat morfologi burung puyuh bisa dilakukan pada umur 1 hari dengan tingkat keberhasilan $92,72 \%$.
\end{abstract}

Kata kunci : Burung puyuh, sexing, dan morfologi.

\section{ABSTRACT}

JAPANESE QUAIL (Coturnix coturnix japonica) SEXING BASED ON
MORPHOLOGY. The purpose of this research was to determine the success of sexing if done earlier. This research was conducted in the cages of a quail farm from April $1^{\text {st }} 2014$ until May $18^{\text {th }}$ 2014. The materials used were 110 male and female day old quails for the first repetition and 100 male and female day old quails for the second repetition, commercial feed $\mathrm{CP} 11$, vitastress. The equipments used in this research were 60 watt light bulb, brooder, digital scale, and a digital camera.The observation was conducted from the first day when the quails just hatched until the quails were 3 weeks of age. The data were analayzed in a descriptive way. The results showed that sexing morphologically can be done in day one with a success rate of $92,72 \%$.

Keywords : Quails, sexing, morphology

\section{PENDAHULUAN}

Burung Puyuh (Coturnix coturnix japonica) memiliki potensi untuk di kembangkan, karena permintaan akan telur burung puyuh cukup tinggi dan harganya relatif dapat dijangkau oleh masyarakat. 
Tujuan umum beternak burung puyuh untuk menghasilkan telur konsumsi. Oleh sebab itu, keberadaan burung puyuh jantan tidak diperlukan karena burung puyuh betina dapat bertelur tanpa burung puyuh jantan.Selain itu, konsumsi ransum burung puyuh jantan lebih banyak dari pada burung puyuh betina. Burung puyuh jantan kurang efisien dijadikan sebagai puyuh pedaging, hanya diperlukan untuk usaha pembibitan, tetapi dengan jumlah sedikit. Berbagai permasalahan yang muncul dalam beternak burung puyuh petelur tidak hanya produksinya yang tidak sesuai harapan tetapi juga ditemukan burung puyuh jantan. Hal ini dapat terjadi karena, saat umur 1 hari atau 1 minggu peternak tidak dapat membedakan antara puyuh jantan dan puyuh betina. Pada umumnya peternak baru dapat membedakan burung puyuh jantan dan betina saat mereka berumur tiga minggu atau lebih, dimana secara morfologi perbedaan antara keduanya sudah terlihat jelas. Oleh sebab itu, suatu penelitian dilakukan untuk dapat membedakan burung puyuh jantan dan betina berdasarkan morfologi melalui warna bulu sayap, paruh, dan kaki (shank), saat burung puyuh berumur kurang dari tiga minggu. Semakin cepat, peternak dapat menentukan jenis kelamin dari burung puyuh, semakin efisien dalam pengelolaan, dan semakin akurat perhitungan biaya ransum. Hal ini sejalan dengan pendapat Thear (1998), bahwa penentuan sex puyuh sangat penting untuk pemeliharaan secara komersial agar dapat dilakukan sesuai dengan tujuan pemeliharaan.

Sexing pada burung puyuh uumnya dilakukan pada umur 3 minggu, dimana pada umur tersebut dengan mudahnya peternak dapat membedakan puyuh jantan dan puyuh betina hanya dengan melihat warna bulu (down/feather colour). Warna bulu puyuh betina pada bagian leher dan dada bagian atas warnanya lebih terang serta terdapat totol-totol cokelat tua, sedangkan puyuh jantan bulu dadanya berwarna cinnamon/cokelat muda.Vali(2011), menyatakan bahwa lebih mudah mengidentifikasi jenis kelamin puyuh setelah tiga minggu, karena warna bulu dada puyuh jantan sangat jelas terlihat perubahannya menjadi cokelat kemerahan. Perubahan warna bulu dada hanya terjadi pada burung puyuh jantan, tidak terlihat pada burung puyuh betina. Cara lain yang dapat dilakukan untuk identifikasi jenis kelamin pada puyuh adalah dengan melihat ukuran tubuh, dimana ukuran tubuh puyuh betina lebih besar dari yang jantan (Vali dan Doosti, 2011).

Vali dan Doosti(2011), menyatakan bahwa melakukan sexing dengan melihat perbedaan warna bulu pada flok ternak puyuh pada umur di bawah umur 
tiga minggu adalah sangat sulit, namun menurut beberapa peternak (personal communication) mereka telah melakukan sexing dini pada puyuh hanya dengan melihat perbedaan warna bulu. Hal ini lebih sederhana, murah dan tidak menyebabkan stress pada puyuh.

Laporan atau publikasi tentang keakurasian metode tersebut pada puyuh usia dini yang dihasilkan dari suatu prosedur yang sistematik dan pengukuran yang reliabel belum ada sampai saat ini. Oleh sebab itu, suatu penelitian akan dilakukan untuk lebih memperjelas apakah metode penentuan kelamin dini pada puyuh hanya dengan melihat perbedaan warna bulu sayap, warna paruh, dan warna shank (kaki) memang akurat dan akhirnya dapat meminimalisir biaya dalam suatu usaha peternakan.

Berdasarkan latar belakang yang telah dikemukakan, maka yang menjadi permasalahan ialah apakah sexing berdasarkan morfologi pada burung puyuh dapat dilakukan lebih awal dari umur 3 minggu.Tujuan penelitian ini dilakukan untuk mengetahui seberapa besar keberhasilan sexing burung puyuh apabila dilakukan lebih awal.

\section{MATERI DAN METODE PENELITIAN}

Penelitian dilakukan selama \pm 6 minggu mulai tanggal 1April 2014 sampai 18Mei 2014, yang meliputi persiapan selama 3 hari, dan 42 hari penelitian yang bertempat di Peternakan puyuh. Bahan yang digunakan dalam penelitian ini ialah, burung puyuh umur satu hari, dan ransum komersial CP11 Pokhpand. Brooder di perlukan untuk meletakan puyuh yang baru menetas. Brooder ini dilengkapi dengan lampu pijar 60 watt, serta tempat makan dan minum.

\section{Metode Penelitian}

1. Mengambil DOQ dari mesin tetas Saat puyuh menetas dan bulu sudah kering, sebanyak 110 ekor puyuh dikeluarkan secara acak dari mesin tetas dan satu-persatu burung puyuh ditimbang. Bersamaan dengan itu dilakukan pengamatan warna atau corak bulu sayap, warna paruh, dan warna kaki (shank).Juga dilakukan pengambilan gambar bagian punggung, sayap, paruh dan kaki dari beberapa ekor burung puyuh. Setelah selesai melakukan penimbangan dan pengamatan, maka didapat diperoleh kelompok puyuh jantan sebanyak 52 ekor dan kelompok puyuh betina sebanyak 58 ekor. Kemudian kelompok puyuh jantan dan betina dimasukkan ke dalam kotak yang 
terpisah untuk dapat di pindahkan ke kandang kotak (brooder).

2. Puyuh dikandangkan

Masing-masing kelompok puyuh dimasukkan ke dalam kandang kotak yang didalamnya telah tersedia makanan dan air minum yang diberi Vitastress. Puyuh diberi makan dua kali sehari, dan alas kandang (koran) diganti setiap hari.

3. Pengamatan dilakukan pada burung puyuh saat berumur 1 minggu, 2 minggu, 3 dan 3 minggu. Masingmasing dari kelompok puyuh jantan dan betina diambil beberapa ekor burung puyuh dan dilakukan pengambilan gambar pada bagian sayap, paruh, dan kaki untuk melihat perubahan morfologi yang terjadi dari setiap ekor burung puyuh.

4. Tahapan 1 sampai 4 dilakukan dua kali, agar data yang diperoleh lebih akurat.

\section{Teknik Penentuan Sexing}

Penetuan jenis kelamin dilakukan umur 1 hari, 1 minggu, 2 minggu, dan 3 minggu. Jantan dan betina dipisahkan dengan melihat warna bulu, paruh, dan shank. Selanjutnya jantan dan betina tetap dipelihara sampai umur 3 minggu untuk paha, dan ekor (Gambar 2). Pertumbuhan bulu yang cepat terdapat pada bagian memastikan keberhasilan sexing dari burung puyuh.

\section{Variabel yang diamati}

Persentase sexing berdasarkan perubahan warna bulu, warna paruh, dan warna shank umur 1 hari 1 minggu, 2 minggu, dan 3 minggu.

\section{Analisis Data}

Data dianalisis secara deskriptif dengan melihat keberhasilan sexing dini burung puyuh berdasarkan warna bulu,warna paruh, warna shank umur 1 hari, 1 minggu, 2 minggu, dan 3 minggu.

\section{HASIL DAN PEMBAHASAN}

\section{Perbedaan Warna Bulu Sayap Burung Puyuh Jantan dan Betina Umur 1 Hari}

Burung puyuh mengalami tahapan pertumbuhan setelah proses penetasan. Sari et al, (2013) menyatakan bahwa pada saat menetas tubuh burung puyuh sudah ditutupi bulu, berbeda dengan tubuh burung merpati, dimana pada saat menetas belum memiliki bulu (telanjang pada saat menetas) atau jika tumbuh bulu, jumlahnya sangat sedikit dan jarang. Bagian yang ditumbuhi bulu pada burung puyuh saat baru menetas terlihat pada dada, sayap, punggung, leher, bahu, 
sayap. Secara morfologi warna bulu jantan dan betina burung puyuh sudah terlihat perbedaannya setelah menetas.

Berdasarkan pengamatan menunjukkan bahwa hasil sexing pada burung puyuh jantan umur satu hari,bagian punggung (dorsal/dorsum) terdapat 3 garis berwarna hitam memanjang sampai bagian ekor (caudal), dan diantara tiga garis tersebut bulu terlihat berwarna kuning.Jadi ada satu garis memanjang pada bagian tengah (midline) dan dua garis lainnya berada memanjang disisi kiri (left lateral) dan sisi kanan (right lateral) bagian punggung badan (Gambar 3). Pada burung puyuh betina umur satu hari, bagian punggung badan (dorsal) juga memiliki 3 garis berwarna cokelat tua memanjang sampai bagian ekor (caudal), dan diantara 3 garis tersebut bulu terlihat berwarna cokelat muda. Sehingga pola garis pada bagian punggung badan burung puyuh betina hampir sama dengan pola garis pada bagian punggung badan burung puyuh jantan, hanya berbeda pada warna bulu yang membentuk pola garis tersebut.

Berdasarkan hasil pengamatan pada bagian sayap burung puyuh jantan dan burung puyuh betina umur 1 hari telah terlihat bulu halus (natal plumages). Warna bulu halus yang menutupi sayap burung puyuh jantan terlihat seperti garis hitam dan kuning dari ujung sayap (phalanx 2) sampai pada bagian pangkal sayap (humerus), sedangkan warna bulu halus yang menutupi sayap burung puyuh betina terlihat seperti garis cokelat muda dan cokelat tua dari ujung sayap (phalanx 2) sampai pada bagian pangkal sayap (Gambar 4). Berdasarkan pengamatan dilapangan, pola warna sayap burung puyuh betina dan pola warna sayap burung puyuh jantan hampir sama hanya berbeda pada warna bulu yang membentuk pola atau corak tersebut. Hasil pengamatan menunjukkan, pertumbuhan bulu sayap primer burung puyuh baik jantan maupun betina mulai terlihat pada umur 4 hari.Pada bagian ujung sayap (phalanx 2) sampai pada batas persendian tulang radialeulnare dan carpometacarpus (phalanx 1,2atau alula) terlihat adanya pertumbuhan seperti sedotan (calamus) pada permukaan tepi kulit sayap baik pada jantan dan pada betina. Bulu (down natal) terlihat bertambah panjang dan berwarna hitam dengan bercak cokelat keemasan pada burung puyuh betina. Pertumbuhan bulu sayap sekunderpanjang daerah tulang (radius ulna) belum terlihat karena bulu yang terlihat masih sama dengan bulu pada saat baru menetas. Sedangkan pada burung puyuh betina, bulu (down natal) juga terlihat lebih panjang hanya berwarna cokelat tua dengan bercak cokelat muda. Sama seperti pada burung puyuh jantan, pertumbuhan bulu sayap sekunder pada burung puyuh betina juga belum 
terlihat dengan jelas (Gambar 5).

\section{Perbedaan Warna Bulu Sayap Umur 1 Minggu}

Berdasarkan pengamatan warna bulu pada kelompok burung puyuh umur 1 minggu, jumlah burung puyuh jantan dan betina masih pada ulangan pertama yaitu 52 puyuh jantan dan 58 puyuh betina. Pengamatan berikutnya pada ulangan kedua jumlah burung puyuh jantan dari 45 ekor menjadi 49 ekor dan untuk burung puyuh betina berubah dari 55 ekor menjadi 51 ekor. Setelah diamati lebih seksama pada kelompok burung puyuh betina terdapat 4 ekor warna dan corak bulu cenderung seperti warna dan corak bulu jantan, sehingga harus dipindahkan ke kelompok ternak puyuh jantan. Perubahan warna menyebabkan kekeliruan dalam pengamatan. Lambey et al, (2013) menyatakan burung jenis ini termasuk burung monomorfik yaitu sulit dibedakan berdasarkan warna bulu. Pertumbuhan bulu dan perubahan warna bulu antara burung puyuh jantan dan burung puyuh betina semakin terlihat jelas pada umur 1 minggu. Sesuai dengan pendapat Genchev et al, (2008) dalam hasil penelitiannya menyatakan pada umur 7 hari sampai 10 hari terjadi perkembangan yang intensif pada bagian sayap, ekor, dan bulu tersembunyi di area dada. Bulu sayap yang bertumbuh semakin banyak dan semakin panjang, warna bulu yang terlihat pada kedua kelompok burung puyuh semakin memudar sehingga hanya terlihat seperti bercak-bercak. Warna bulu sayap burung puyuh jantan terlihat semakin hitam gelap dengan bercak-bercak cokelat keemasan, sedangkan pada bulu sayap burung puyuh betina, warnnya cokelat muda dengan bercak kekuningan (Gambar $6)$.

\section{Perbedaan Warna Bulu Sayap Umur 2 Minggu}

Pada pengamatan warna bulu, kedua kelompok ternak burung puyuh umur 2 minggu tidak ada perubahan jumlah dari masing-masing kelompok ternak penelitian. Kelompok puyuh jantan pada ulangan pertama berjumlah 52 ekor dan kelompok puyuh betina 58 ekor. Pada ulangan ke dua kelompok burung puyuh jantan berjumlah 49 ekor dan kelompok puyuh betina berjumlah 51 ekor. Berdasarkan pengamatan, buluburung puyuh pada umur 14 hari tumbuh lebih banyak dan arah pertumbuhan semakinjelas. Bulu primer semakin bertambah panjang dan lapisan-lapisan bulu pada permukaan punggung sayap, alur pertumbuhannya semakin jelas dan teratur. Bulu pada bagian humeral tract 
sampai perbatasan pertumbuhan alula semakin lebat dan bulu sekunder juga sudah nampak jelas dan teratur baik pada kelompok puyuh jantan dan kelompok puyuh betina. Pada umur ini, warna bulu sayap puyuh jantan dari pangkal sayap (humerus) sampai ujung (bagian phalanx 2) berwarna hitam pekat dengan bintikbintik samar kecil berwarna putih serta cokelat keemasan pada bagian ujung (barbs) bulu, kecuali pada bulu primer dan bulu sekunder. Sedangkan, warna bulu sayap puyuh betina dari pangkal sayap (humerus) sampai ujung (bagian phalanx 2) berwarna abu-abu kecokelatan. Sama seperti puyuh jantan, bulu primer dan bulu sekunder puyuh betina berwarna cokelat secara keseluruhan (Gambar 7). Jadi, pada umur 2 minggu, warna dan corak bulu burung puyuh jantan dan burung puyuh betina semakin jelas perubahannya.

\section{Perbedaan Warna Bulu Sayap Umur 3 Minggu}

Warna dan corak bulu pada kedua kelompok ternak burung puyuh umur 3 minggu tidak ada perubahan jumlah dari masing-masing kelompok ternak penelitian. Pada ulangan pertama kelompok puyuh jantan berjumlah 52 ekor dan kelompok puyuh betina 58 ekor. Pada ulangan kedua kelompok burung puyuh jantan berjumlah 49 ekor dan kelompok burung puyuh betina berjumlah 51 ekor. Kelompok burung puyuh jantan dan kelompok burung puyuh betina terlihat seragam karena tidak ada perbedaan warna yang mencolok.

Pada umur 3 minggu bulu burung puyuh terlihat semakin lebat dan arah pertumbuhan semakin lebih jelas. Bulu dari bagian humeral tract sampai pada ujung (phalanx 2) juga semakin lebat atau kelihatan tebal baik pada kelompok puyuh jantan maupun kelompok puyuh betina. Kelompok lapisan bulu pada permukaan punggung sayap, alur pertumbuhannya semakin jelas dan teratur. Saat pengamatan umur 2 minggu ukuran panjang bulu primer dan sekunder berbeda, namun pada umur 3 minggu ukuran panjang dari bulu primer dan sekunder memiliki ukuran yang hamper sama. Perbedaan panjang bulu sayap ini diduga di pengaruhi oleh faktor suhu yang terlalu panas sehingga menyebabkan rontok bulu dan terjadi pertumbuhan bulu yang tidak merata. Hickman et al, (2007) menyatakan bahwa sayap pada burung memiliki ukuran dan bentuk yang bervariasi karena perbedaan perkembangan dan disesuaikan dengan habitat.

Pada umur 3 minggu, warna bulu sayap burung puyuh jantan dari pangkal sayap (humerus) sampai ujung (phalanx 2) berwarna hitam pekat dengan bintik-bintik samar kecil berwarna cokelat keemasan 
pada bagian ujung (barbs) bulu. Bintikbintik putih pada bagian ujung bulu sayap burung puyuh jantan tidak terlihat.Bulu sayap primer dan sekunder pada puyuh jantan tidak mengalami perubahan warna. Sedangkan warna bulu sayap puyuh betina pada umur 3 minggu dari pangkal sayap (humerus) sampai ujung(phalanx 2) tidak banyak mengalami perubahan, tetap berwarna abu-abu kecokelatan. Sama seperti burung puyuh jantan, warna bulu primer dan bulu sekunder burung puyuh betina tidak mengalami perubahan. Secara keseluruhan burung puyuh betina berwarna cokelat muda (Gambar 8). Jadi, pada umur 3 minggu warna bulu burung puyuh jantan dan betina semakin jelas perbedaanya. Sesuai dengan pendapat Genchevet al,(2008) yang menyatakan bahwa pada umur 3 minggu warna bulu sayap eksternal pada beberapa bagian tubuh telah berkembang dengan baik, menjadi semakin tebal dan semakin kontras.

\section{Warna Paruh Burung Puyuh Umur 1 Hari}

Burung puyuh memiliki paruh yang berbeda, dimana setiapbentuk paruh danwarna paruh burung disesuaikan dengan jenis makanan. Berdasarkan pengamatan warna paruh pada burung puyuh jantan dan betina umur 1 hari terlihat berbeda. Setelah diamati lebih seksama, warna paruh burung puyuh jantan seperti warna cokelat tua pada bagian maxilla baik dari pangkal atau bagian operculum hingga mandible. Sedangkan pada paruh burung puyuh betina pada bagian maxilla berwarna cokelat muda. Perubahan warna ini hanya terjadi pada bagian ujung dari paruh burung puyuh betina saja sedangkan pada bagian pangkal atau operculum berwarna kuning kecokelatan. Kemudian pada paruh bagian mandible dari burung puyuh betina memilki warna merah muda. Jadi, warna paruh dari burung puyuh jantan dan betina umur 1 hari sudah terlihat perbedaanya baik pada bagian maxilla, mandible, dan operculum (Gambar 9). Dilihat dari bentuk paruh burung puyuh jantan dan betina memilki bentuk yang sama. Berbeda dengan dengan jenis burung lainnya seperti dalam penelitian Lambey et al,(2013) menyatakan burung jantan memiliki paruh lebih panjang dan lebih besar dari betina. Lebih jelasnya lagi Stewart et al, (2014) menyatakan paruh adalah struktur badan yang terdapat pada mulut burung, dimana setiap burung memilki bentuk ukuran paruh yang berbeda-beda.

\section{Warna Paruh Burung Puyuh Umur 1 Minggu}

Berdasarkan pengamatan, menunjukkan warna paruh burung puyuh 
pada umur 1 minggu terlihat adanya pertumbuhan dan perubahan warna paruh baik pada burung puyuh jantan dan betina. Pada umur ini, paruh burung puyuh semakin bertambah pertumbuhannya dan warna paruh burung puyuh jantan pada bagian maxilla berwarna cokelat tua (mendekati hitam) hingga pada bagian pangkalnya atau bagian operculum. Selanjutnya pada bagian mandible berwarna cokelat. Bagian maxilla pada paruh burung puyuh betina berwarna cokelat muda dan bagian mandible berwarna kuning kecokelatan (Gambar $10)$.

\section{Warna Paruh Burung Puyuh Umur 2 Minggu}

Pada umur 2 minggu warna paruh burung puyuh jantan dan betina semakin jelas perubahannya. Warna paruh puyuh jantan dari bagian maxilla berwarna hitam pekat hingga bagian operculum dan pada bagian mandible berwarna cokelat tua. Sedangkan, warna paruh puyuh betina pada bagian maxilla berwarna cokelat tua, perubahan warna ini juga terlihat pada bagian operculum dan mandible berwarna cokelat. Paruh burung puyuh pada umur 2 minggu tumbuh lebih panjangdan warnanyasemakin jelas. Paruh bagian maxilla danmandible semakin bertambah panjang.
Hasil pengamatan menunjukkan burung jantan memiliki variasi warna paruh yaitu cokelat tua mulai dari ujung hingga pangkal, serta warna cokelat muda di ujung paruh kemudian warna coklat tua kehitam-hitaman dari bagian tengah sampai pangkal. Pada burung puyuh betina variasi warna paruh terlihat berwarna merah tua di bagian ujung kemudian warna cokelat tua kehitamhitam dari bagian tengah sampai pangkal (Gambar 11).

\section{Warna Paruh Burung Puyuh Umur 3 Minggu}

Warna paruh umur 3 minggu pada puyuh jantan dari bagian pangkal atau operculum sampai bagian maxilla berwarna hitam pekat. Kemudian warna paruh bagian maxilla dan mandible puyuh jantan tidak terjadi perubahan warna lagi. Sedangkan warna paruh puyuh betina pada umur 3 minggu bagian dari maxilla berwarna cokelat tua mendekati warna hitam dan bagian maxilla berwarna cokelat, namun pada bagian pangkal atau operculum berwarna merah muda. Sama seperti puyuh jantan, paruh puyuh betina warnanya tidak mengalami perubahan yang secara keseluruhan berwarna cokelat kehitaman. 


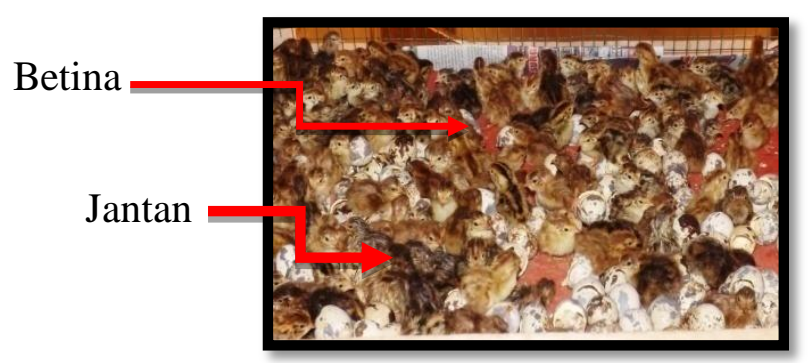

Gambar 2. Puyuh umur 1 hari (Day old quail)

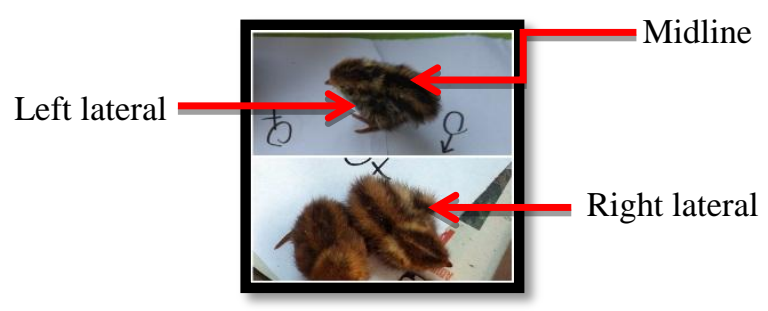

Gambar 2. Warna garis pada burung puyuh jantan dan betina

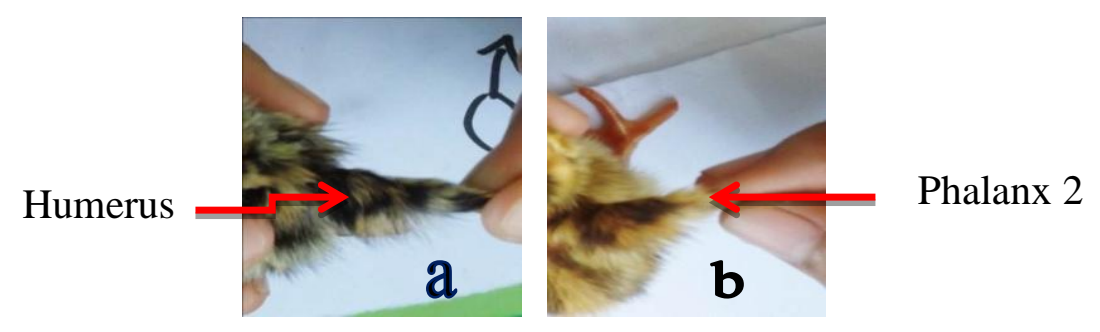

Gambar 3. Warna sayap puyuh umur 1 hari Jantan (a) Betina (b)

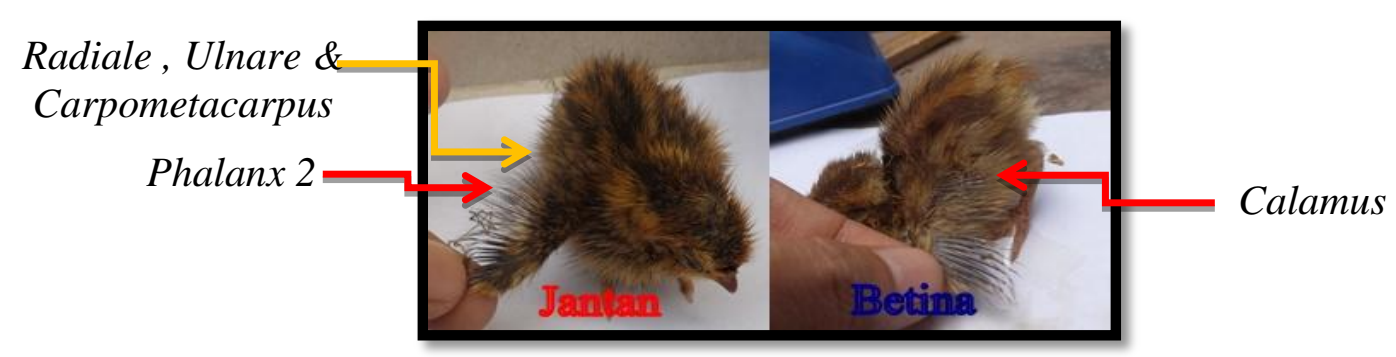

Gambar 4. Pertumbuhan bulu umur 4 hari puyuh jantan danbetina
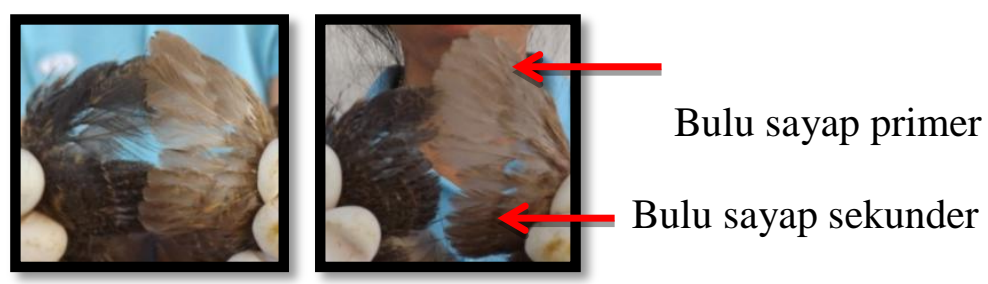

Gambar 5. Warna Sayap Burung Puyuh Jantan dan Betina 

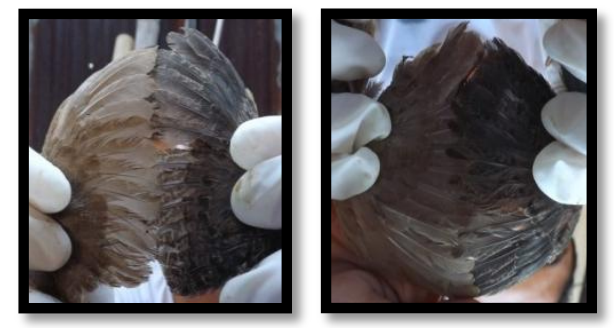

Gambar 6. Warna bulu sayap burung puyuh jantan betina

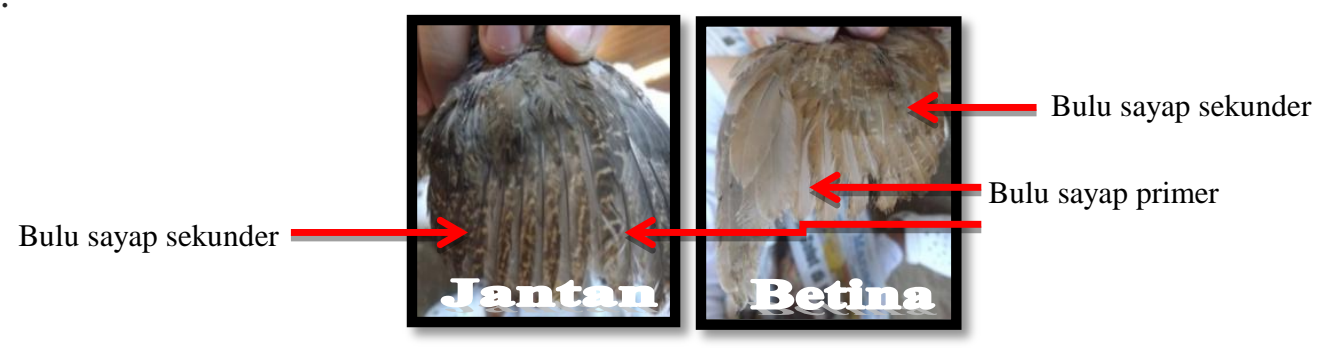

Gambar 7.Warna bulu burung puyuh umur 21 hari
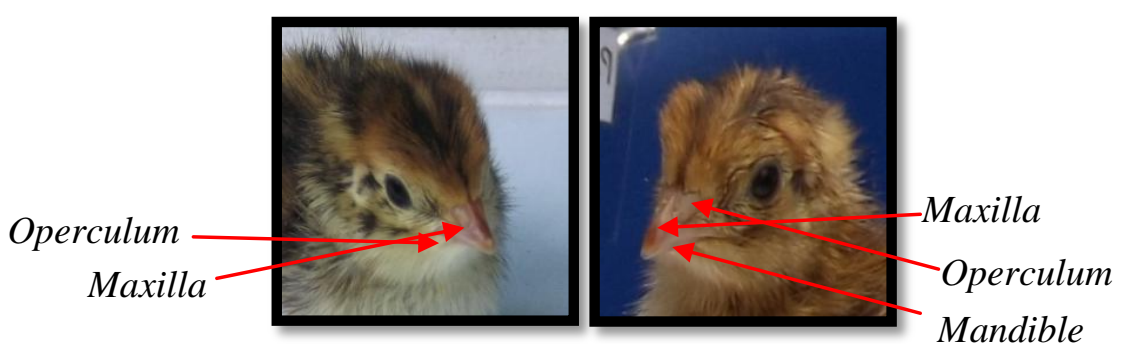

Gambar 8. Warna paruh DOQ jantan dan betina
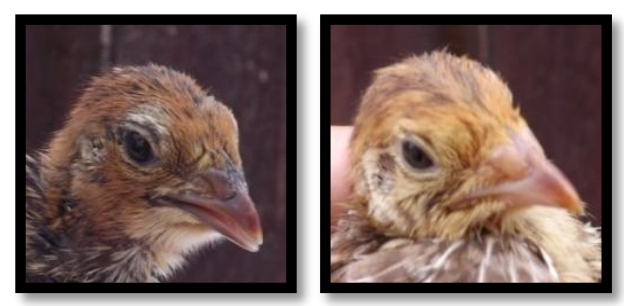

Gambar 9. Warna paruh burung puyuh jantan danbetina umur 1 minggu
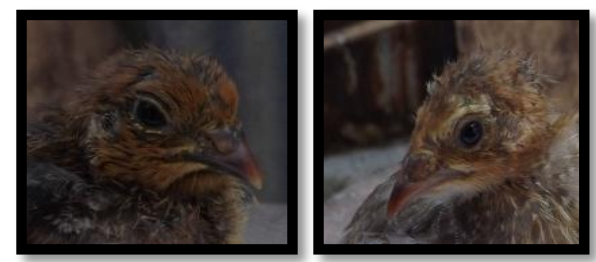

Gambar 10. Warna paruh burung puyuh jantan danbetina umur 2 minggu 

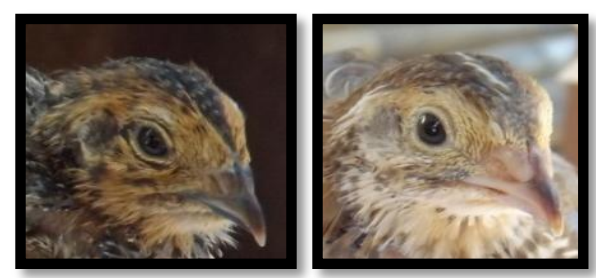

Gambar 11. Warna paruh burung puyuhjantan danbetina umur 3 minggu
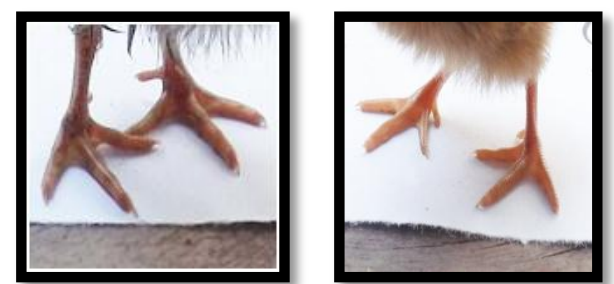

Gambar 12. Warna shank burung puyuh jantan dan betina umur 1 hari

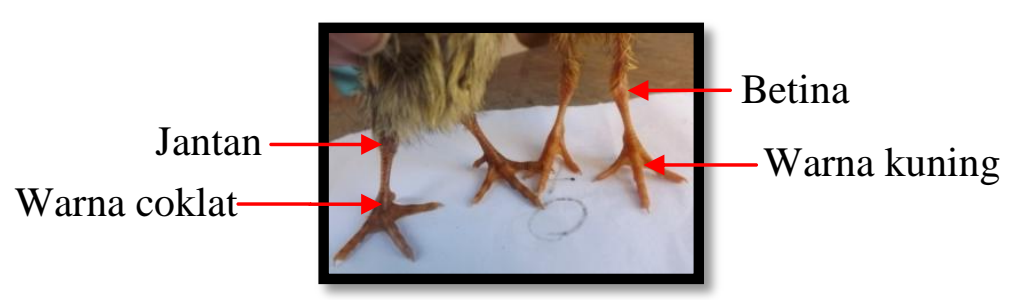

Gambar 13. Warna shank burung puyuh jantan danbetina umur 7 hari

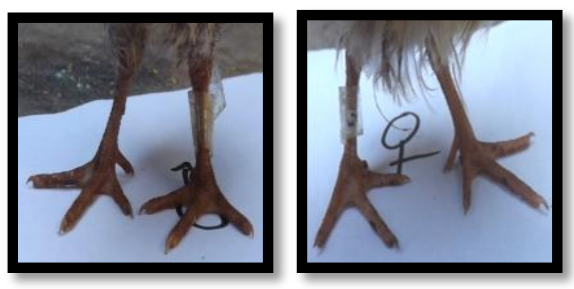

Gambar 14. Warna shank puyuh jantan danjantan umur 2 minggu
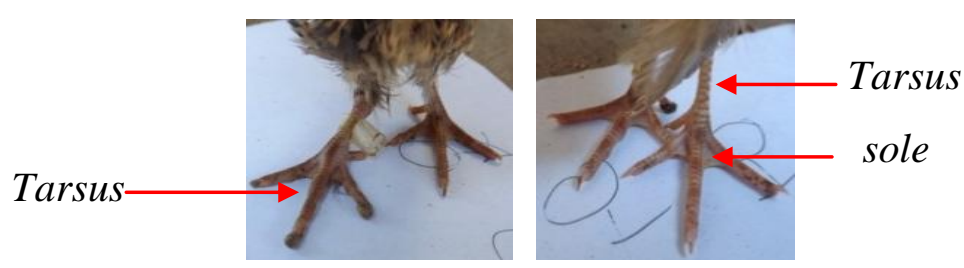

Gambar 15. Warna shank burung puyuh jantan danbetina umur 3 minggu 
Berdasarkan pengamatan, menunjukkan warna paruh burung jantan dan betina umur 3 minggu tidak ada perbedaan yang signifikan dengan warna paruh umur 2 minggu hanya ukurannya yang berbeda yaitu ukuran paruhnya lebih sedikit panjang. Jadi, pada umur 3 minggu warna paruh burung puyuh jantan dan betina semakin jelas perbedaannya (Gambar 12).

\section{Warna Shank Burung Puyuh Umur 1}

Hari

Berdasarkan pengamatan, menunjukkan burung puyuh memliki bentuk dan warna kaki (shank) yang berbeda baik jantan dan betina. Hasil pengamatan menunjukkan burung puyuh memiliki bentuk shank yang pendek warna shank burung jantan umur satu hari berwarna kuning kecokelatan dengan bercak cokelat yang sangat jelas terlihat di bagian tarsus (tibiotarsus) kaki sampai ke bagian kuku, sedangkan warna shank burung betina yaitu kuning dengan bercak cokelat muda tetapi belum terlihat jelas (Gambar 13).

\section{Warna Shank Burung Puyuh Umur 1}

\section{Minggu}

Pada pengamatan umur 1 minggu, menunjukkan ukuran shank lebih panjang dengan warna shank burung jantan yaitu cokelat muda dan terlihat adanya bercak cokelat tua pada bagian tarsus. Warna shank pada burung betina berwarna kuning dengan bercak-bercak cokelat muda di bagian jari kaki (Gambar 14).

\section{Warna Shank Burung Puyuh Umur 2 Minggu}

Warna shank burung jantan umur 2 minggu yaitu cokelat tua dengan bercakbercak hitam sedangkan shank burung betina yaitu cokelat muda dengan bercakbercak cokelat. Dari beberapa ekor burung yang diamati warna shank umur 2 minggu puyuh jantan memiliki perbedaan yaitu cokelat tua, dengan bercak cokelat muda, dan cokelat. Shank dengan warna cokelat tua tidak terlihat lagi bercak bercaknya karena sudah ditutupi dengan warna dasar kaki burung. Sedangkan shank puyuh betina yang diamati tidak memiliki perbedaan warna yaitu cokelat muda dengan bercak-bercak warna cokelat (Gambar 15).

\section{Warna Shank Burung Puyuh Umur 3 Minggu}

Berdasarkan hasil pengamatan, warna shank pada umur 3 minggu yaitu berwarna cokelat kehitaman yang terlihat di permukaan kulit kaki puyuh jantan. Sedangkan pada burung puyuh betina berwarna kuning dan terlihat bercakbercak cokelat yang terlihat di bagian 
Tabel 1. Jumlah Burung Puyuh berdasarkan Sexing pada berbagai tingkat umur

\begin{tabular}{llcccccc}
\hline & & \multicolumn{3}{c}{ Ulangan 1 } & \multicolumn{3}{c}{ Ulangan 2 } \\
No & Umur & Jantan & Betina & $\begin{array}{c}\text { Persentase } \\
(\%)\end{array}$ & Jantan & Betina & $\begin{array}{c}\text { Persentase } \\
(\%)\end{array}$ \\
\hline 1 & 1 Hari & 52 & 58 & & 45 & 55 & \\
2 & 1 Minggu & 52 & 58 & $100 \%$ & 49 & 51 & $92.72 \%$ \\
3 & 2 Minggu & 52 & 58 & $100 \%$ & 49 & 51 & $100 \%$ \\
4 & 3 Minggu & 52 & 58 & $100 \%$ & 49 & 51 & $100 \%$ \\
\hline
\end{tabular}

permukaan kulit kaki burung puyuh betina (Gambar 16). Hasil pengamatan menunjukkan semakin bertambah umur dari burung puyuh semakin jelas perubahan warna yang terjadi.

\section{Persentase keberhasilan sexing}

Sexing burung puyuh umur 1 hari pada ulangan pertama adalah 52 ekor jantan dan 58 ekor betina. Kemudian sexing dilakukan kembali pada minggu pertama, minggu kedua, dan minggu ketiga untuk melihat apakah terjadi perubahan pada jumlah burung puyuh hasil sexing pada pengamatan sebelumnya. Dari pengamatan tersebut memiliki tingkat keberhasilan yang sama sebesar 100\% untuk puyuh jantan dan betina.

Pada ulangan kedua dapat dilihat bahwa sexing burung puyuh umur 1 hari adalah 45 ekor jantan dan 55 ekor betina. Kemudian sexing dilakukan kembali pada minggu pertama, dan diperoleh jumlah burung puyuh jantan 49 ekor dan puyuh betina 51 ekor dengan persentase $92,72 \%$.
Sexing pada minggu kedua dan ketiga, memiliki tingkat keberhasilan yang sama sebesar 100\% untuk puyuh jantan maupun betina.

\section{KESIMPULAN}

Berdasarkan hasil dan pembahasan dapat disimpulkan bahwa sexing dengan melihat perubahan morfologi warna bulu burung puyuh umur 1 hari bisa dilakukan dengan tingkat keberhasilan 92,72\%.

\section{DAFTAR PUSTAKA}

Akhmad H.S.N., Edhy. S., dan Heni S. P.,2013. Pengaruh pencahayaan dan intensitas cahaya terhadap konsumsi pakan, pertambahan bobot badan, dan konversi pakan pada burng puyuh jepang (Coturnix coturnix japonica).Universitas Brawijaya Malang.

Ensminger ME. 1992. Poultry Science.Ed ke-3. USA: Interstate

Hickman, C.P., L.S Roberst, S.L. Keen, A. Larson dan D. J. Eisenhour. 2007. Animal Diversity. Mc Graw-Hill, New

York. 
Koyong S., Wungow H.R.,Lambey L., Laatung S. 2014. Morfometri burung weris (Gallirallus philippensis) dan Burung weris (Galliralus torquatus) di Kotamobagu Sulawesi Utara.Zootek 34:51-56 .

Lambey L. J., Noor RR, Wasmen M, Duryadi D.2013. Karakteristik morfologi perbedaan jenis kelamin, dan pendugaan umur burung weris (Gallirallus philippensis) di Minahasa Sulawesi Utara, Veteriner 14:228-2238.

Listiyowati, E, dan Roospitasari, K 2009, Burung Puyuh Tata Laksana Budidaya Secara Komersil. Penebar Swadaya,Jakarta

Noble S Proctor dan Patrick J.Lynch.(1993). Manual of Ornithology Avian Structures \& Function.

Tambunan. G. M , W. Seregat., dan E. Suprijatna. $2013 \quad$ Pengaruh penambahan kotoran wallet dalam ransum terhadap performans burung puyuh jantan umur 0-5 minggu.Animal agriculture, 2.(1)105-113

Sari W, Kamal S, dan Umami S, 2013. Perbandingan tipe danperkembangan bulu pada tiga jenis unggas. Jurusan Biologi Fakultas MIPA Unsyiah, Banda Aceh.

Thear K (1998). Keeping quail (Aguide to domestic and commercialmanagement) third edition, published by Broad Leys Publishing Company Buriton House, station Road, Newport,
Saffron Waldan, Essex CB11 3PL, UK.

Vali Nasrollah \& Abbas Doosti, 2011.Molecular study for the sex identification in Japanese quail.African of Biotechnology 10(80). 